\title{
CORRECTION
}

\section{Correction to: ASD symptoms in adults with ADHD: a preliminary study using the ADOS-2}

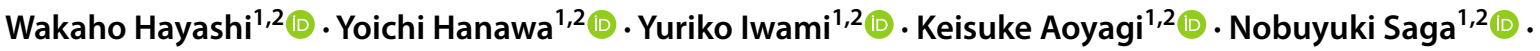 \\ Dan Nakamura ${ }^{1,2}$. Akira Iwanami ${ }^{1,2}$
}

Published online: 13 August 2021

(c) Springer-Verlag GmbH Germany, part of Springer Nature 2021

\section{Correction to: \\ European Archives of Psychiatry and Clinical Neuroscience \\ https://doi.org/10.1007/s00406-021-01250-2}

In the original article published, one of the rating scale name in Method section is mentioned incorrectly. We used CAARS Self-Report: Long version and NOT Screening version for our study.

Incorrect and Current state:

Conners' Adult ADHD Rating Scale Self-Report: Screening Version (CAARS-S:SV-J)

Correct:
Conners' Adult ADHD Rating Scale Self-Report: Long Version (CAARS-S:L-J)

The original article can be found online at https://doi.org/10.1007/ s00406-021-01250-2.

Wakaho Hayashi

wakahoh@med.showa-u.ac.jp; wakaho15@gmail.com

1 Department of Psychiatry, Showa University School of Medicine, 6-11-11 Kitakarasuyama, Setagaya-ku, Tokyo 157-8577, Japan

2 Department of Psychiatry, Showa University Karasuyama Hospital, 6-11-11 Kitakarasuyama, Setagaya-ku, Tokyo 157-8577, Japan 